\title{
RELATO DE PESQUISA: PROJETO CIÊNCIA E PERFORMANCE, ESTUDO DA CONFERÊNCIA INTERNACIONAL SOBRE COMUNICAÇÃO PÚBLICA DA CIÊNCIA E TECNOLOGIA
}

PROFA.DRA. CRISTINA MARQUES GOMES DEPARTAMENTO DE CIÊNCIAS DA COMUNICAÇÃO UNIVERSIDADE FEDERAL DE SANTA MARIA (UFSMM)

E-MAIL:CRISTINA@USP.BR

PROF.DR. ARTHUR E. A. BELLONI DEPARTAMENTO DE ARTES CÊNICAS UNIVERSIDADE FEDERAL DE SANTA MARIA (UFSM) E-MAIL: ARTHUREABELLONI@YAHOO.COM.BR

SABRINA FERREIRA GASPAR DA SILVA BOLSISTA DE INICIAÇÃO CIENTÍFICA (IC) VOLUNTÁRIA DEPARTAMENTO DE CIÊNCIAS DA COMUNICAÇÃO UNIVERSIDADE FEDERAL DE SANTA MARIA (UFSM)

E-MAIL: SABRINAFGS@HOTMAIL.COM

HTTP://DX.DOI.ORG/10.5902/2316882X23473 
RELATO DE PESQUISA: PROJETO CIÊNCIA E PERFORMANCE, ESTUDO DA CONFERÊNCIA INTERNACIONAL SOBRE COMUNICAÇÃO PÚBLICA DA CIÊNCIA E TECNOLOGIA

Resumo: O presente artigo está relacionado ao Projeto de Pesquisa "Ciência e Performance: estudo da Conferência Internacional sobre Comunicação Pública da Ciência e Tecnologia". Apresentamos aqui os resultados parciais de um questionário disponibilizado no dia 13 de maio de 2014, logo após a Conferência na Bahia-Brasil, numa lista de discussão da Network for the Public Communication of Science and Technology (PCST). O questionário obteve 42 respostas de pesquisadores de diferentes países, com predominância do Brasil, Índia, Estados Unidos e Itália, seguidos da Austrália e da Inglaterra.

INFORME DE INVESTIGACION: PROYECTO DE INVESTIGACIÓN "CIENCIA Y PERFORMANCE: ESTUDIO DE LA CONFERENCIA INTERNACIONAL SOBRE COMUNICACIÓN PÚBLICA DE LA CIENCIA Y LA TECNOLOGÍA"

Resumen: El presente artículo está relacionado con el Proyecto de Investigación "Ciencia y Performance: estudio de la Conferencia Internacional sobre Comunicación Pública de la Ciencia y la Tecnología”. Presentamos aquí los resultados parciales de una encuesta realizada en el día 13 de mayo de 2014, poco después de la Conferencia en Bahía-Brasil, en una lista de discusión de la Network for the Public Communication of Science and Technology (PCST). El cuestionario obtuvo 42 respuestas de investigadores de diferentes países, con predominio de Brasil, India, Estados Unidos e Italia, seguidos de Australia e Inglaterra

\section{RESEARCH REPORT: RESEARCH PROJECT "SCIENCE AND PERFOR- MANCE: STUDY OF INTERNATIONAL PUBLIC COMMUNICATION OF SCIENCE AND TECHNOLOGY CONFERENCE"}

ABSTRACT: The present work is a report Concerning the Research Project "Science and Performance: Study of International Public Communication of Science and Technology Conference". We present here the partial results of a questionnaire made available on May 13, 2014, shortly after the Conference in Bahia, Brazil, in a mailing list of the Network for the Public Communication of Science and Technology. The survey received 42 responses from researchers of different countries, especially Brazil, India, United States and Italy, followed by Australia and England.

Rev.Cad. Comun. Santa Maria, v.20, n.2, art 11, p.186 de 205, maio/ago.2016 


\section{CONTEXTUALIZAÇÃO DA PROBLEMÁtICA E OBJETIVOS}

O desenvolvimento histórico da comunicação científica (CC) pode ser dividido, grosso modo, segundo Vickery (2000) em sete grandes períodos, a saber: as civilizaçõos antigas (cerca de 600 a.C), a cultura clássica (600 a.C até 500 d.C), a medieval (500-1450), a etapa da "revolução científica" (1450-1700), e cada um dos séculos subsequentes, a saber, século XVIII, XIX e XX. A partir de cada fase é possível identificar as principais atividades científicas e técnicas, os papéis sociais relevantes para a ciência em tal e qual período e os mecanismos decorrentes do avanço nas tecnologias da comunicação (VICKERY, 2000), dentre diversas outras correlações - uma das quais, diretamente associada à própria História da Ciência $(\mathrm{HC})$ e à CC. Nesse âmbito, vários estudos relacionados à primeira (HC) podem ser aplicados, de diferentes formas, à segunda (CC) e vice-versa. Bons exemplos dessa conjuntura advém de autores como Merton, Price, Bernal, Menzel, Le Coadic e Ziman.

Entre tantos pensadores que se depararam em esmiuçar o conceito de ciência, através da concepção de seus limites, sua amplitude, suas consequências, suas perspectivas, Popper $(1972,1978)$ preconizou a demarcação entre o que é ou não científico; Kuhn (1987) trouxe a noção de movimento, através das revoluções científicas e seus paradigmas; Weber nos explicitou o desencantamento da ciência e do mundo; Merton (1968) se preocupou em discutir a dimensão social da ciência. Entre os autores contemporâneos, Latour (1994) e Spinak (1996) destacam a importância da cooperação no mundo científico atual (PISCIOTTA, 2006, p. 124).

Todos esses autores e o arsenal de teorias e requisitos epistemológicos que os ronda formam o que poderíamos designar como a "base" para a construção do que se tem ou o que se pensa ou, ainda, o como moldamos nossas investigações em torno da CC e, por conseguinte, da própria Comunicação Pública da Ciência; são, por assim dizer, o suporte principal que sustenta o sistema e seus processos recorrentes e vindouros. Sobrepostos a tal "base", para além da conotação teórica, estão os primeiros "alicerces" que emergem, nomeadamente, a partir do desenvolvimento da imprensa, no século XV, na Europa, quando assistimos à proliferação dos livros e, consequentemente, a difusão de informações e, posterior-

Rev.Cad.Comun. Santa Maria, v.20, n.2, art 11, p.187 de 205, maio/ago.2016 
mente, o surgimento das disciplinas, universidades, associações, dos inúmeros periódicos e a consolidação da comunicação científica nos moldes do que a temos hoje. A imprensa - e, consequentemente, o importante papel desempenhado pela figura de Johann Gensfleish Gutenberg - pode ser apontada como a primeira grande transformação na forma como a ciência, tal qual nós a concebemos hoje, foi sendo pensada, articulada e divulgada.

Em termos históricos, ainda, no século XVII, acreditava-se que a maioria dos estudos estava, em certo sentido, inserida em alguma "modalidade de investigação filosófica" e só com o decorrer dos anos, a ciência (e deduzidamente a CC) foi se organizando e se estruturando como tal. Organização essa que possibilitou, junto a outros fatores locais, que várias disciplinas fossem configuradas e sistematizadas. Algumas surgiram no espectro de uma especialização dentro de uma grande área, outras em decorrência de conjunturas históricas e econômicas das sociedades e algumas continuam a surgir da fusão e/ou interdisciplinariedade temática - quase que num processo inverso ao anterior. Cada uma, no entanto, acabou por desenvolver alguns princípios básicos sobre o que consiste ou como se desenvolve - uma pesquisa a partir de diferentes métodos e abordagens e, consequentemente, gerando formas específicas de comunicação científica. Encontramos, inclusive, dentro de um mesmo campo, diferentes modos de abordagem investigativa.

Cada comunidade científica, além disso, apresenta, por vezes, velocidades e processos específicos de pesquisa, partilha, recolha, utilização e preservação das informações, dados e do próprio conhecimento que são muitas vezes, também, acentuados por diferenças regionais e institucionais/acadêmicas e que impactam, além do desenvolvimento da própria CC, em maior ou menor grau, na aceitação ou recusa de certos artefatos tecnológicos ou nas transformações, de outra ordem, relacionadas ao sistema - em Física, por exemplo, "elementos eletrônicos" acabam por substituir as revistas "tradicionais", enquanto em outras áreas menos. Nessa linha, o estudo de Kling e McKim (2000) prima por analisar as diferenças "comportamentais" de cada disciplina diante da CC, numa conjugação que nos permite compreender o que o futuro "irá, possivelmente, oferecer". Já Crawford, Hurd, e Weller (1996) e Hurd (2000), a partir dos atributos específicos de cada matéria, contribuem para o desenvolvimento da área a partir da deliberação de novos modelos científicos.

Rev.Cad. Comun. Santa Maria, v.20, n.2, art 11, p.188 de 205, maio/ago.2016 
Além das interfaces entre a História da Ciência, a disciplinaridade e a CC que são derivadas, principalmente, do contexto histórico e seguem uma sequência razoavelmente cronológica, existem aspectos outros que estão atrelados aos próprios conceitos, ou seja: "ninguém pode afirmar quando foi que se começou a fazer pesquisa científica e, por conseguinte, quando, pela primeira vez, houve comunicação científica. A resposta a isso depende principalmente da definição que se tenha do que seja 'pesquisa"” (Meadows, 1974). O termo "comunicação científica", no entanto, foi empregado pela primeira vez por John Bernal, durante a primeira metade do século XX, e assim exemplificado: "a comunicação científica compreende o amplo processo de geração e transferência de informação científica" (Christovão; Braga, 1997, p.40 apud VALÉRIO, 2005).

As conceituações podem ser consideradas a partir da própria diversidade (e, por vezes, complexidade) com que são apontadas por diferentes linhas de pesquisa e teóricos ao longo da história. Cada qual, partindo dos seus próprios pressupostos, acaba por trilhar uma construção singular de raciocínio que tangencia toda a sua pesquisa no âmbito da comunicação científica. Daí, podemos constatar que uma série de interpretações pode ser aferida. Até a própria noção de CC, tradicionalmente relacionada ao tripé pesquisa, sistema e sociedade, também, passou (ou passa) por variações - ora o processo de "investigação" está incorporado ao universo da comunicação científica , ora é um elemento "à parte". Alguns autores consideram a CC como o conjunto da "investigação + retroalimentação do sistema pelas pesquisas que são produzidas + a divulgação dos resultados para a sociedade" e, para outros, a "comunicação científica" é simplesmente o "ato de comunicar os resultados da pesquisa entre os pares" em oposição a "divulgação científica" como sinônimo da "divulgação para os leigos". No âmbito desta, as interpretações também são bem variadas, adentrando a terminologia da "divulgação didática" (nas escolas, etc), a "primária" (entre os pares) e a "divulgação científica propriamente dita" (como acontece, por exemplo, nas diversas revistas redigidas em um linguajar coloquial com o propósito de comunicar aos diferentes públicos, princípios ou descobertas científicas), etc.

A Comunicação Pública da Ciência pode ser entendida a partir de quarto modelos (Lewenstein; Brossard, 2006). O primeiro, "modelo do déficit", emerge, na metade do século XIX, a partir da visão da própria comunidade científica inglesa. Tem por

Rev.Cad.Comun. Santa Maria, v.20, n.2, art 11, p.189 de 205, maio/ago.2016 
objetivo disseminar informações ao público leigo, partindo do pressuposto da ignorância do público em relação a temas científicos. Está diretamente conectado à ideia de alfabetização científica. O segundo, denominado de "modelo contextual", surge, na década de 1980, e começa a se preocupar com a valorização de experiências culturais e saberes prévios. Reconhece o papel da mídia na ampliação dos conceitos científicos. Não considera as respostas do público que recebe informações unidirecionais e em situações específicas. Essas informações, no entanto, não fornecem elementos suficientes para uma visão política e mais crítica da ciência, uma vez que considera apenas seus efeitos benéficos. Seria, portanto, apenas uma versão mais refinada modelo do déficit. Já o terceiro modelo, o de "experiência leiga”, que surge no início da década de 1990, a partir das críticas dos modelos anteriores, ao contrário do modelo contextual, considera o conhecimento, os saberes e as histórias, crenças e valores de comunidades reais. Considera que os cientistas com frequência não são razoáveis, e, eventualmente, até arrogantes sobre o nível de conhecimento do público, falhando ao não fornecer elementos necessários para uma real tomada de decisão do público em situações políticas conflitantes. Trata-se, portanto, de um modelo mais dialógico e democrático. O modelo mais aceito, após a década de 1990 e nos dias atuais, é o de "participação pública", que não só reconhece, como valoriza a opinião do público e seu direito de participar das decisões sobre as políticas públicas de CT\&I. É considerado um modelo dialógico por essência, uma vez que pressupõe a existência de fóruns de debate com a participação de cientistas e do público. Ainda assim, é alvo de algumas críticas por estar mais centrado na discussão das políticas científicas em lugar da compreensão pública da ciência". Enciclopédia Intercom de comunicação. São Paulo: Sociedade Brasileira de Estudos Interdisciplinares da Comunicação, volume 1, 2010.

Quando exploramos estritamente, portanto, o conceito de divulgação científica encontramos um arcabouço bem completo de linhas teóricas e de interpretações - das mais "clássicas" às "alternativas", como por exemplo, a transposição da "divulgação" (modelos ditos deficitários) para o "diálogo" (modelos dialógicos), subtraindo a centralidade do pesquisador, nos moldes dos trabalhos desenvolvidos pelo "Nordic Network for the Study of the Dialogic Communication of Research" e outros. Tais linhas advém de uma série de atores sociais diferentes - jornalistas, cientistas, profissionais de museus de ciência, etc - e, consequentemente, de um conjunto de disciplinas díspares, até pela própria característica "trans-

Rev.Cad.Comun. Santa Maria, v.20, n.2, art 11, p.19o de 205, maio/ago.2016 
versal" da divulgação científica/comunicação pública da ciência.

A partir, portanto, dessas considerações gerais, adentramos nosso objeto de estudo que, no contexto da divulgação científica, está centrado, principalmente, na " 13 a Conferência Internacional sobre Comunicação Pública da Ciência e Tecnologia” que aconteceu em 2014 no Brasil. Tal conferência está inserida na Rede PCST:

\begin{abstract}
A Rede Internacional de Comunicação Pública da Ciência e da Tecnologia (PCST, em sua sigla em inglês) é uma rede de indivíduos de diversas partes do mundo que produzem e estudam na área de comunicação pública da C\&T. A rede PCST inclui: jornalistas científicos, profissionais de museus e centros de ciência, diretores de teatro científico, pesquisadores acadêmicos estudam aspectos da PCST, cientistas que lidam com o público, relações públicas e assessores de imprensa de instituições científicas e vários outros profissionais interessados nesses temas. A rede PCST patrocina conferências internacionais, discussões virtuais e outras atividades para fomentar o diálogo entre diferentes grupos de pessoas interessadas em PCST, levando ao enriquecimento mútuo que atravessa fronteiras profissionais, culturais, internacionais e disciplinares. A Rede PCST procura promover novas ideias, perspectivas, métodos e questões intelectuais e práticas. Objetivos da rede PCST: Estimular a comunicação pública da ciência e tecnologia (PCST); Incentivar a discussão de práticas, métodos, questões éticas, políticas, econômicas e sociais, estruturas conceituais, além de outros temas envolvendo PCST; Unir praticantes de PCST, pesquisadores que estudam PCST, e as comunidades científicas envolvidas com PCST; Unir profissionais de diferentes culturas e países ao redor do mundo, tanto de países desenvolvidos quanto em desenvolvimento, interessados em PCST; Proporcionar oportunidades de encontros e interações virtuais' .
\end{abstract}

A conferência abarca a categoria "Performance" - como um dos seus "formatos de apresentação", assim como "papers individuais", "painéis", "oficinas", "Show Tell \& Talk", e outros e é desse diferencial que surgiu o interesse no desenvolvimento dessa pesquisa. Para tanto, formulamos os seguintes objetivos específicos: 1 . Identificar e analisar as interfaces da

1 Fonte: Rede PCST. Disponível em: <http://www.pcst-2014.org/index.php/pt-BR/ pcst-network>, acessado em 15 de maio de 2013.

2 Vide a página <http://www.pcst-2014.org/index.php/pt-BR/chamada-de-trabaIhos>.

Rev.Cad.Comun. Santa Maria, v.20, n.2, art 11, p.191 de 205, maio/ago.2016 
performance com a Divulgação Científica (aqui lidando tão somente com uma pesquisa bibliográfica centrada na coleta de dados relacionados aos artigos disponíveis, nos últimos 3 anos, nas principais bases de dados internacionais - Web of Science, Scopus, e outras - que abordam a temática da "comunicação pública da ciência" em interface com a "performance/ arte"); 2. Mapear o que já foi feito no campo da performance ao longo das doze edições da "Conferência Internacional sobre Comunicação Pública da Ciência e Tecnologia"; 3. Coletar impressões do público-alvo sobre as performances da $13^{\text {a }}$ Conferência Internacional sobre Comunicação Pública da Ciência e Tecnologia que aconteceu em maio de 2014 em Salvador, Bahia, Brasil. Sobre esse último objetivo, apresentamos abaixo um breve relato parcial da pesquisa que teve caráter quali-quantitativo, tendo o questionário como técnica de coleta de dados e o grupo-foco os pesquisadores da Rede PCST. Cabe salientar que consideramos, na presente pesquisa, a "performance" como forma artística (Performance Art) entrecruzada com a performance concebida como experiência e competência ${ }^{3}$.

\section{RESULTADOS PARCIAIS}

A Rede PCST, de 1989 a 2014, organizou encontros em 12 diferentes países, sendo 6 na Europa, 2 na Ásia, 1 na África, América do Norte, América do Sul e Austrália. A Conferência da América do Sul (a $13^{a}$ ) foi sediada no Brasil, mais especificadamente na Bahia (Salvador), entre os dias 5 e 8 de maio de 2014 tendo como tema principal a "Comunicação pública da ciência para a inclusão social e o engajamento político".

\footnotetext{
Entre os objetivos está estimular debates sobre o engajamento público em temas relacionados a ciência e tecnologia. Para o presidente da Rede PCST, Toss Gascoigne, se a ciência pretende recuperar a confiança da sociedade, perdida nos últimos vinte anos, ela deve se preparar para ser mais aberta ao público.Segundo Gascoigne, temas como mudanças climáticas e programas de vacinação são exemplos que demonstram alguma oposição do público à ciência. "Novos termos, como 'apropriação social da ciência' enfatizam que as pessoas querem ter direito de participar de decisões relacionadas a temas científicos", ex-
}

3 Sobre o cruzamento destas duas “visões" da performance, ver: FÉRAL, Josette. Além dos limites: teoria e prática do teatro. São Paulo: Perspectiva, 2015. p. 113-119

Rev.Cad. Comun. Santa Maria, v.20, n.2, art 11, p.192 de 205, maio/ago.2016 
plica o presidente da PCST. Suzanne Cheveigné, membro do Comitê Científico da PCST, reforça a opinião do presidente da Rede: "a comunicação tem de se adaptar às perguntas do público e às demandas daqueles com quem se está falando". Cheveigné enfatiza, ainda, que a realização da conferência PCST ${ }^{4}$ no Brasil vai ao encontro dos objetivos e da natureza da Rede, que busca sua internacionalidade. "O fato de a conferência ser no Brasil é extremamente importante, porque será a primeira vez que a PCST ocorrerá no sul da América. Dessa forma, mais pesquisadores sul-americanos poderão participar do debate e opinar sobre o estado da arte na comunicação da ciência". À fala de Cheveigné, o presidente da Rede, Toss Gascoigne, acrescenta que a realização do evento no Brasil será uma oportunidade para impulsionar a comunicação científica e para estimular a geração de novos projetos e alianças internacionais ${ }^{5}$.

O questionário, abaixo descrito, foi disponibilizado dia 13 de maio de 2014, logo após a Conferência na Bahia, numa lista de discussão ${ }^{6}$ da Rede PCST e obteve 42 respostas de pesquisadores de diferentes países, assim distribuídas quanto às variáveis "idade" e "nacionalidade":

Figura 1 e Tabela 1 - questão 1

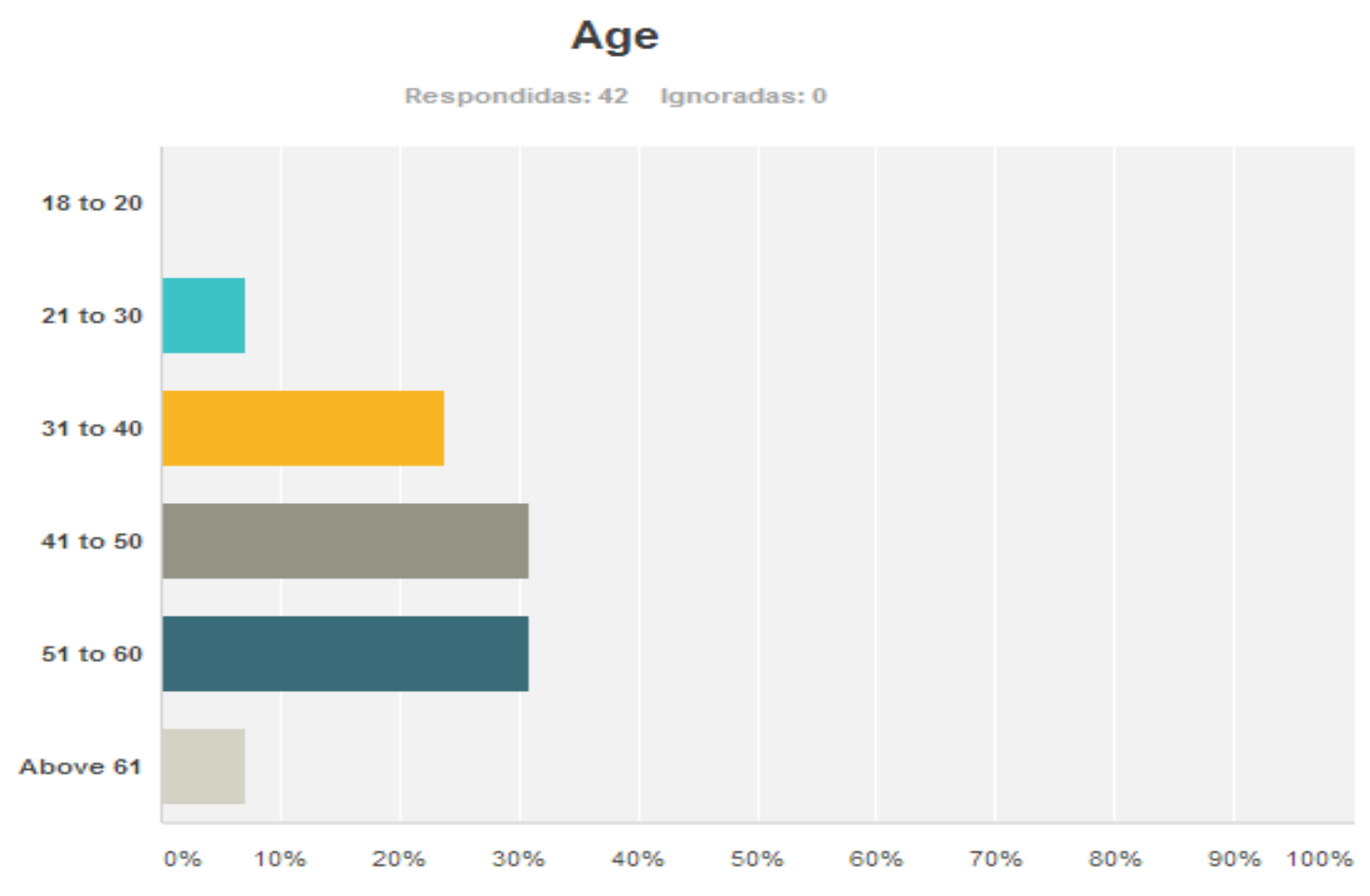

4 http://www.pcst-2014.org/index.php/pt-BR/pcst2014

5 Disponível em: <http://www.pcst-2014.org/index.php/pt-BR/news/14-portugues/ latest-news-home/81-materia>, acessado em 2 de janeiro de 2015.

6 https://www.pcst.co/discussion

Rev.Cad.Comun. Santa Maria, v.20, n.2, art 11, p.193 de 205, maio/ago.2016 


\begin{tabular}{l|lc}
\hline Opçöes de resposta & Respostas & \\
\hline$\quad 18$ to 20 & $0,00 \%$ & 3 \\
\hline$\quad 21$ to 30 & $7,14 \%$ & 10 \\
\hline$\quad 31$ to 40 & $23,81 \%$ & 13 \\
\hline$\quad 41$ to 50 & $30,95 \%$ & 13 \\
\hline$\quad 51$ to 60 & $30,95 \%$ & 3 \\
\hline$\quad$ Above 61 & $7,14 \%$ & 42 \\
\hline Total & & \\
\hline
\end{tabular}

Questão 2. Nationality and Place of Residence Tabela 2 - questão 2

\begin{tabular}{|c|c|}
\hline Pais & $\begin{array}{c}\text { Quantidade de } \\
\text { pesquisadores } \\
\text { respondentes }\end{array}$ \\
\hline Brasil & 6 \\
\hline India & 5 \\
\hline Estados Unidos & 4 \\
\hline Itallia & 4 \\
\hline Austrablia & 3 \\
\hline Inglaterra & 3 \\
\hline Portugal & 2 \\
\hline Dinamarca & 2 \\
\hline França & 2 \\
\hline Africa do Sul & 2 \\
\hline Alemanha & 2 \\
\hline Turquia & 1 \\
\hline Filipinas & 1 \\
\hline Espanha & 1 \\
\hline Croacia & 1 \\
\hline Argentina & 1 \\
\hline Mexico & 1 \\
\hline Holanda & 1 \\
\hline Total & 42 \\
\hline & \\
\hline & \\
\hline
\end{tabular}

Rev.Cad.Comun. Santa Maria, v.20, n.2, art 11, p.195 de 205, maio/ago.2016 
Obtivemos retorno de pesquisadores provenientes de 18 países diferentes, sendo a maior porcentagem oriunda do Brasil (6 pessoas), seguido da Índia (com 5), Estados Unidos e Itália (4 cada). A diversidade dos respondentes confere à pesquisa uma relevância geográfica significativa e a presença maior do Brasil se justifica em função do evento ter ocorrido no país e o questionário ser direcionado justamente ao público-alvo da Conferência.

A terceira questão, ainda com a intenção de caracterizar o perfil do respondente, estava relacionada ao grau de escolaridade e obteve as seguintes respostas: um pesquisador com título de pós-doutorado, 26 doutores, 1 doutorando, 13 mestres e somente 1 bacharel, ou seja, a maioria possui o título de doutor.

Já a quarta pergunta ("What is your main connection with science communication?”) apresentou os seguintes resultados:

Tabela 3 - questão 4

\begin{tabular}{|c|c|c|c|}
\hline Opções de resposta & $\nabla$ & Respostas & $\nabla$ \\
\hline Professional practice in science communication & & $42,86 \%$ & 18 \\
\hline Research on science communication & & $54,76 \%$ & 23 \\
\hline Teaching/Training in science communication & & $35,71 \%$ & 15 \\
\hline Scientist who takes part in science communication & & $19,05 \%$ & 8 \\
\hline Student of science communication & & $0,00 \%$ & 0 \\
\hline$\nabla$ Other & & $2,38 \%$ & 1 \\
\hline
\end{tabular}

A questão acima demonstra a participação ativa de pesquisadores que, direta ou indiretamente, estão envolvidos com a temática da comunicação pública da ciência - 54,76\% responderam "research on science communication"; $42,86 \%$ "professional practive in science communication" e $35,71 \%$ "traching/training in science communication".

Na pergunta seguinte, o foco foi saber se o respondente, na condição de espectador, acompanhou, ou não, as performances que acontece- 
ram durante a programação da Conferência ${ }^{1}$ objeto de estudo - obtivemos $50 \%$ de respostas afirmativas e outras $50 \%$ negativas.

Figura 2 - questão 5

Respondidas: 42 Ignoradas: 0

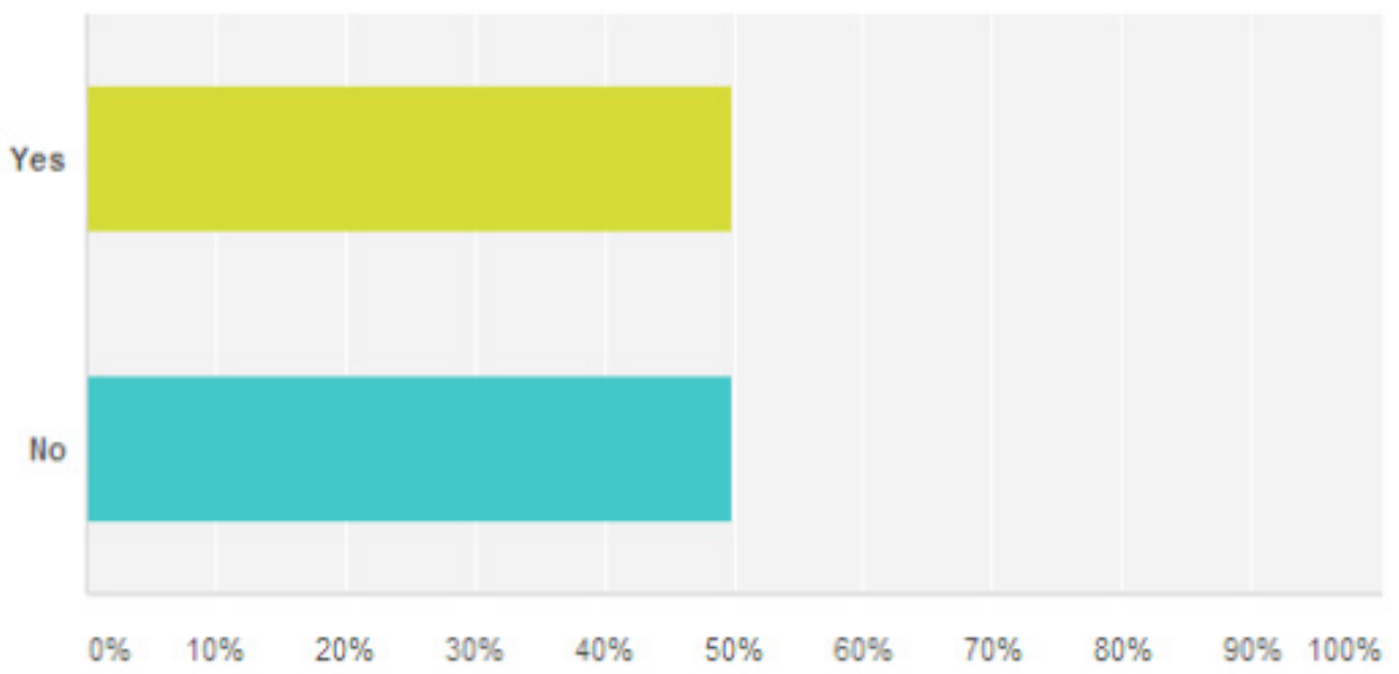

Com uma abordagem qualitativa sobre como o respondente classificaria as performances da 13a. Conferência, a penúltima questão congregou os seguintes resultados:

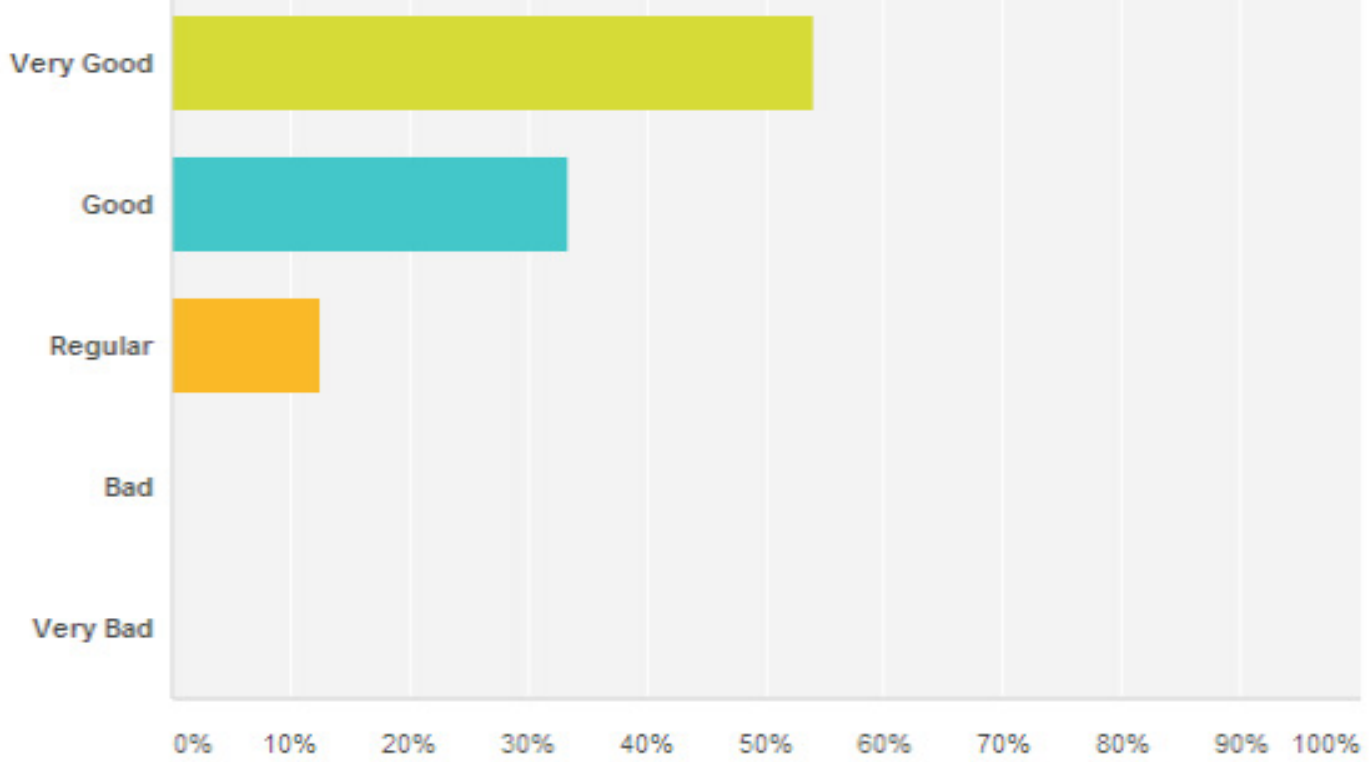

1 Veja o programa completo em: <http://www.pcst-2014.org/index.php/pt-BR/ program>.

Rev.Cad.Comun. Santa Maria, v.20, n.2, art 11, p.197 de 205, maio/ago.2016 
A última pergunta buscava averiguar se a performance pode ser um instrumento, em comparação com outros métodos e ferramentas, eficaz na comunicação pública da ciência - 54,11\%, ou seja, 22 respondentes assinalaram a alternativa "yes", para 20,51" (8) "it is indifferent", 15,38\% (6) "have no opinion" e 7,69\% (3) responderam "no".

Figura 4 - questão 7

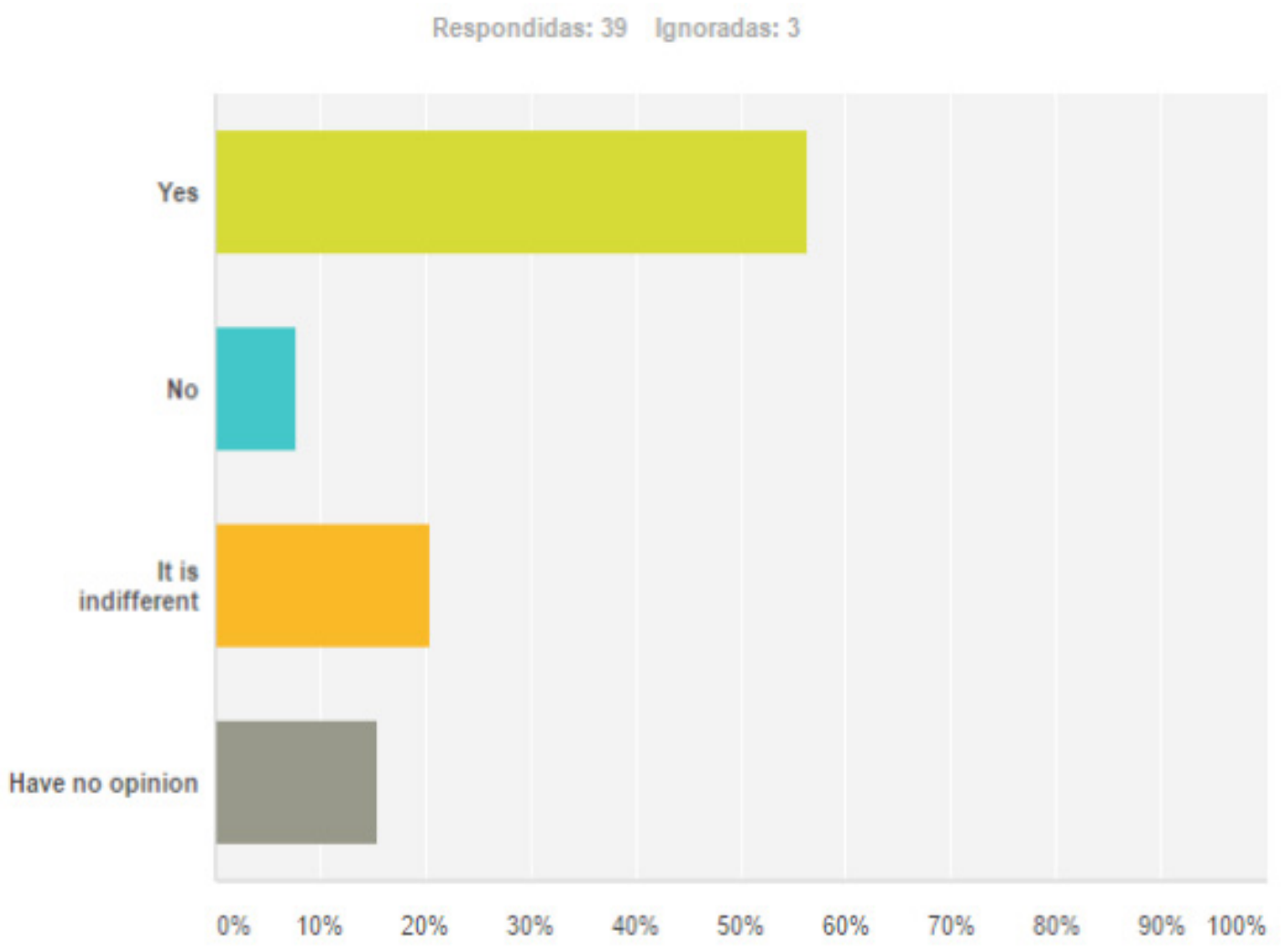

O espaço final do questionário era livre para cada respondente expressar qualquer tipo de opinião sobre o binômio Performance e Divulgação Científica e as observações apontadas revelaram, sobremaneira, uma diversidade de concepções sobre o assunto. Em meio a tais considerações, a performance, por vezes, é encarada como um "meio" profícuo para se promover a divulgação científica - assim como workshops, aulas-espetáculo, teatro científico, etc. -, podendo, nesse sentido, auxiliar de forma considerável na reflexão sobre temas relacionados à ciência e à sociedade. Um dos respondentes, por exemplo, cita uma performance a que assistira sobre questões éticas relacionadas ao campo da neurociência e cuja apresentação teria sido muito eficaz no sentido de salientar as problemáticas em torno desses temas. Este mesmo respondente alega, no entanto, que a performance tem que ser "muito boa" pois, caso contrário, o efeito, em termos de "aprendizagem" do público, acaba sendo o 
oposto do almejado.

Para outro respondente, a performance pode ser um instrumento capaz de "chamar a atenção do público" que, a partir de um primeiro contato (via performance) com um determinado assunto, buscará, a posteriori, mais informações sobre o conteúdo tratado. A ação performática foi ainda elencada como uma atividade eficaz para introdução de um tema de cunho científico e, nesse sentido, relevante para exploração dos impactos éticos e sociais de uma questão científica de investigação - principalmente, na área médica, conforme sugere um dos participantes da pesquisa. Também respondeu a pesquisa uma pessoa que se considera "um dos pioneiros em usar a arte para a comunicação pública da ciência" e que, em função disso, concordava em absoluto com a importância desse meio para a difusão da ciência.

Comparada a outros meios de comunicação pública da ciência, a performance também foi encarada positivamente, em função dos aspectos "emocionais" que supostamente mobilizaria - e que, por sua vez, acabariam por "envolver" o público. Nesse sentido, a performance seria um canal propício para tornar a divulgação científica acessível. Um respondente que assistiu à apresentação da performance "The Big Van Theory", por exemplo, qualifica a experiência como uma forma divertida, engraçada e informativa de divulgar a ciência para um público diversificado.

Esse papel de destaque da performance como meio propício à divulgação científica, contudo, não é atribuído sem ressalvas. Um dos respondentes, por exemplo, atenta para o problema de o evento performático "deturpar" ou "simplificar" questões relativas ao universo científico. Outro destaca a necessidade de se promover frequentes adaptações e mudanças no "roteiro" da performance de acordo com as demandas e especificidades de uma determinada audiência - o que acaba configurando um grande desafio à medida que muitas vezes o trabalho é direcionado para um público cujo perfil é por demais heterogêneo. Um terceiro partícipe - que diz ter assistido às performances na plenária de abertura - considera a apresentação "divertida" mas, ao mesmo tempo, relata não ter apreendido ou assimilado absolutamente nada. De acordo com um outro respondente ainda, para elevar o nível de assimilação/absorção de informação relativas à ciência por parte do público, outras modalidades de ação - leituras, palestras, documentários, debates públicos com cientistas, etc., por exemplo - seriam bem mais eficazes que a performance.

Rev.Cad.Comun. Santa Maria, v.20, n.2, art 11, p.199 de 205, maio/ago.2016 
Por outro lado, alguns respondentes minimizaram ou mesmo questionaram a necessidade de apreensão/absorção de conteúdos por parte dos espectadores. De acordo com essa perspectiva, um dos participantes da pesquisa, por exemplo, sustenta que não devemos voltar ao "deficit model" pois as performances não são e não devem ser feitas com o intuito de promover a absorção de um conteúdo - "o público não está lá para absorver. Você não deve controlar, nem querer controlar, o que eles (os espectadores) absorvem". De forma complementar, outro pesquisador resgata a noção de "cultura científica" de acordo com a qual a ciência deve ser integrada à vida cultural como um todo. Nesse sentido, observa, a "absorção" (de conteúdos) se torna um elemento secundário e não a razão mais importante de uma performance que aconteça pela via da comunicação pública da ciência'.

Para além das considerações apontadas pelos respondentes no âmbito da pesquisa - e tendo como referência algumas observações feitas por Jean-François Lyotard (1997) no ensaio Algo como: "comunicação... sem comunicação", apresentado pelo filósofo francês no Colóquio "Arte e Comunicação" realizado na Sorbonne em Outubro de 1985 -, caberia, por fim (e por ora), questionar: Como poderiam as marcas da representação/determinação por conceitos, peculiares às formas tradicionais de comunicação pública da ciência, libertar o jogo constituído pelo componente estético, à medida que, o sentimento estético pressupõe algo que escapa à problemática fundamental da re-presentação (a saber, algo que existe aqui e agora, o lugar e o momento, o que há)? Como não suprimir a comunicabilidade constitutiva desse sentimento que permanece não efetuada pela comunicação de ordem conceptual, argumentativa e tecno-científica, posto que, quando nos situamos nas artes da representação, a questão do aqui e agora passa a ser ocultada? E o aqui e agora, na esteira do pensamento de Lyotard, configura aquilo que desampara e destitui a consciência, o que ela não pode pensar, pois é pura ocorrência, aconteci-

1 Indo ao encontro dessa observação, outra pessoa apontou que as performances apresentadas durante a plenária - uma com enfoque na cultura brasileira (música) e outra na ciência - contribuíram muito para o "clima" da conferência como um todo. O respondente em questão afirma que se identifica muito com essa tradição nas conferências organizadas pela PCST, à medida que ela mobiliza uma consciência cultural atenta ao fato de que a ciência deve sempre refletir o pano de fundo sociocultural no qual ela se insere.

Rev.Cad. Comun. Santa Maria, v.20, n.2, art 11, p.200 de 205, maio/ago.2016 
mento. O que não implica, de modo algum, abdicar da racionalidade, mas, pelo contrário, sugere a mobilização de um pensamento que acolha a presença por uma via que não seja a da intervenção dominadora/controladora. Como observa o próprio Lyotard (1997) no ensaio "O tempo, hoje":

Em definitivo, uma racionalidade não merece o seu nome se recusar a sua responsabilidade no que existe de passibilidade aberta e de criatividade incontrolada, na maior parte das linguagens, incluindo a linguagem cognitiva. Por mais que recuse essa responsabilidade, a racionalidade técnica, científica e econômica mereceria de preferência o nome de "ideologia", se o termo não tivesse, por sua vez, demasiadas pressuposições metafísicas (... Estar apto para receber o que o pensamento não está preparado para pensar, é o que devemos chamar pensar. Esta atitude, já o disse, encontra-se tanto na linguagem reputada racional quanto na poética, na arte e na linguagem habitual, se, pelo menos, for necessário que o discurso cognitivo progrida. Não saberíamos admitir, em consequência, a grosseira separação das ciências e das artes prescritas pela cultura ocidental moderna. Desempenha a tarefa, sabe-se, de relegar as artes e a literatura para a função miserável de distrair os seres humanos do que os preocupa e persegue em permanência, a obsessão de controlar o tempo (...) É no entanto necessário nunca esquecer que, se pensar consiste mesmo em receber o acontecimento, segue-se que não se poderia pretender o pensamento sem se encontrar ipso facto em posição de resistência diante dos processos de controlo do tempo. Pensar é questionar tudo, inclusivamente o pensamento, a questão e o processo. Ora, questionar requer que algo aconteça cuja razão não seja ainda conhecida. Quando pensamos, aceitamos a ocorrência pelo que é: "ainda não" determinada, não a pré-julgamos, nem nos asseguramos dela. É uma peregrinação no deserto. Não podemos escrever sem testemunhar este abismo que é o tempo, quando chega (LYOTARD, 1997, p. 79-80).

Ao se destacar o que existe na comunicabilidade em termos de pura presença, ocorrência, acontecimento, talvez seja possível vislumbrar, no caso da Comunicação Pública da Ciência pela via da performance, uma variedade de exploração performativa de substratos da ciência pautada não pela explicação ou transmissão de informações (o que, na maioria das vezes, ocorre a partir de abordagens estruturadas em fábulas narradas ou representadas), mas antes pelo jogo e pela experimentação com a "matéria científica".

Rev.Cad.Comun. Santa Maria, v.20, n.2, art 11, p.201 de 205, maio/ago.2016 


\section{CONSIDERAÇÕES FINAIS:}

O presente relato compreende os dados parciais de um Projeto de Pesquisa ainda em andamento cujo foco é, principalmente, a $13^{\mathrm{a}}$ Conferência Internacional sobre Comunicação Pública da Ciência e Tecnologia. Apresentamos, pois, os dados descritivos de um questionário aplicado aos pesquisadores da rede PCST, em 2014, cujas variáveis envolviam a idade, a nacionalidade e o país de residência, o grau de escolaridade, a ligação/ contexto com o universo da comunicação pública da ciência, a participação enquanto espectador das performances da Conferência, a opinião sobre as mesmas e, por fim, se a performance pode ser um instrumento, em comparação com outros métodos e ferramentas, eficaz na comunicação pública da ciência. Da pesquisa como um todo, destacamos que são raríssimos os artigos publicados, nos principais indicadores internacionais, que abordam a "comunicação pública da ciência" pela perspectiva da "performance" - considerada aqui, conforme acima referido, como forma artística (Performance Art) entrecruzada com a performance como experiência e competência. Outros resultados da pesquisa foram, em síntese, publicados nos anais da Conferência "Science in Public: Research, Practice, Impact" que ocorreu na University of the West of England, Bristol (Inglaterra), em julho de 2015 sob o título "Science and Performance: A Study of the International Public Communication of Science and Technology Conference" e em outras publicações. 


\section{REFERÊNCIAS:}

COSTA, S. M.,; LIMA, F. C. Gestão do conhecimento científico: proposta de um modelo conceitual com base em processos de Comunicação Científica. In: Ciência da Informação, v.36, p.92-107, 2007.

. Abordagens, estratégias e ferramentas para o acesso aberto via periódicos e repositórios institucionais em instituições acadêmicas brasileiras. In: Liinc em Revista, v.4, n.2, p.218-232, set., 2008.

. Filosofia aberta, modelos de negócios e agências de fomento: elementos essenciais a uma discussão sobre o acesso aberto à informação científica. In: Revista Ciência da Informação. Brasília: v.35, n.2, p.39-50, mai/ago., 2006.

CRAWFORD, S. Y. Scientific Communication an the growth of big science. In: S. Y. Crawford, J. M. Hurd, \& A. C. Weller, From Print to Electronic: The Transformation of Scientific Communication. USA: Information Today, 1996.

FÉRAL, Josette. Além dos limites: teoria e prática do teatro. São Paulo: Perspectiva, 2015.

GOMES, Cristina Marques. Comunicação Científica: Cartografia e Desdobramentos. São Paulo: ECA/USP, 2012 (Tese de Doutorado).

HURD, J. M. Models of Scientific Communications systems. In S. Y. CRAWFORD, J. M. HURD, \& A. W. WELLER, From Print to Electronic: The Transformation of Scientific Communication. USA: Information Today, 1996.

. The transformation of Scientific Communication: a model for 2020. Journal of the American Society for Information Science and Technology , v.51, p.1279$1283,2000$.

. Scientific Communication: new roles and new players. In: Science and Technology Libraries, v.25, n.1-2, p.5-22, 2004.

KLING, R. Learning about information technologies and social change: The contribution of social informatics. In: Information Society, v.16, n.3, p.217-232, 2000.

. The internet and unrefereed scholarly publishing. In: Annual Review of Information Science and Technology, v.38, p.591-631+xix-xx, 2004.

et al. A bit more to it: Scholarly Communication forums as socio-technical interaction networks. In: Journal of the American Society for Information Science and Technology, v.27, 2003.

.; CALLAHAN, E. Electronic journals, the internet, and Scholarly Communication. In: Annual Review of Information Science and Technology, v.37, p.127-177, 2003.

.; MCKIM, Geoffrey. Not just a matter of time: field differences and the shaping of electronic media in supporting Scientific Communication. In: Journal of the American Society for Information Science and Technology, v.51, n.14, p.1306-1320, 1999/2000.

LYOTARD, Jean-François. O inumano - considerações sobre o tempo. Lisboa: Editorial

Rev.Cad.Comun. Santa Maria, v.20, n.2, art 11, p.203 de 205, maio/ago.2016 
Estampa Ltda, 1989.

MEADOWS, A.J. Communication in Science. London: Butterworths, 1974. . Avaliando o desenvolvimento da Comunicação Eletrônica. In: MULLER, Suzana Pinheiro Machado; PASSOS, Edilenice Jovelina Lima. Comunicação Científica. Brasília: Departamento de Ciência da Informação Universidade de Brasília, 2000.

PISCIOTTA, Kátia. Redes sociais: articulação com os pares e com a sociedade. In: POBLACIOM, Dinah Aguiar; WITTER, Geraldina Porto; SILVA, Fernando Modesto da (org). Comunicação e Produção Científica: contexto, indicadores, avaliação. São Paulo: Angellara, 2006.

VALÉRIO, Palmira M. C. Mariconi; PINHEIRO, Lena Vânia Ribeiro. Da Comunicação Científica à divulgação In: TransInformação, v.20, n.2, p.159-169, maio/ago., 2008 - Periódicos científicos eletrônicos e novas perspectivas de comunicação e divulgação para a ciência. Rio de Janeiro: Convênio UFRJ / IBICT, 2005 (Tese de Doutorado).

VICKERY, B. C. Scientific Communication in history. London: The Scarecrow Press, 2000. 


\section{Cristina Marques Gomes}

Doutora em Ciências no Programa de Ciência da Informação - Área de Concentração: Cultura e Informação pela Escola de Comunicações e Artes da Universidade de São Paulo (USP). Docente do Centro de Ciências Humanas e Sociais da Universidade Federal de Santa Maria (UFSM).

\section{Arthur E.A. Belloni}

Doutor em Artes pela Escola de Comunicações e Artes da Universidade de São Paulo (USP). Docente do Centro de Artes e Letras da Universidade Federal de Santa Maria (UFSM).

\section{Sabrina F.G. da Silva}

Acadêmica do Curso de Comunicação Social - Relações Pùblicas da Universidade Federal de Santa Maria (UFSM).

RECEBIDO EM: 11/06/2016

APROVADO PARA PUBLICAÇÃO:14/07/2016 